\title{
Das ruas para a sala de aula: potencialidades dos elementos gráficos vernaculares nas práticas educativas durante o processo de letramento infantil
} From the streets to the classroom: the potentialities of vernacular graphic elements
in educational practices during the process of developing children's literacy

\author{
Mariana Hennes, Solange Coutinho
}

letreiros populares, educação, letramento, materiais didáticos, memória gráfica

\begin{abstract}
Os letreiros populares são manifestações vernaculares urbanas que se constituem em um rico sistema de informação iconográfico e semântico. Apesar da área do Design vir desempenhando um importante papel com estudos desses artefatos como parte da identidade cultural e memória gráfica de grupos sociais locais, esse tipo de manifestação ainda está longe de ter todas as suas potencialidades exploradas. Ao ponderar possíveis conexões entre essa temática e outras áreas de conhecimento encontrou-se no campo da Educação, uma oportunidade de diálogo multidisciplinar a ser investigado. Durante o processo de letramento infantil brasileiro (ainda conhecido como alfabetização), uma das principais ferramentas de ensino são os materiais didáticos efêmeros, confeccionados pelos próprios professores e utilizados em sala de aula. Embora tais materiais tenham a intenção de estimular a busca e a geração de conhecimento por parte das crianças, ainda é comum o uso de referências gráficas estrangeiras, massificadas ou deslocadas das suas realidades cotidianas. Assim, este artigo objetiva provocar reflexões acerca do papel do Design/Educação, propondo a investigação de práticas educativas que permitam, ao educando, mais do que a mera leitura de palavras, mas a leitura do mundo a sua volta e o reconhecimento de uma cultura própria como conteúdo educativo, passível de ser estudado na vivência escolar e extraescolar.
\end{abstract}

popular lettering, education, literacy, educational materials, graphic memory

Popular lettering is a manifestation of urban vernaculars that forms extremely rich iconic, semantic information systems. Although the design area has contributed greatly towards the study of these artifacts as part of the cultural identity and graphic memory of local social groups, the true potentialities of these types of manifestations have not been fully explored. When considering connections between this theme and other areas of knowledge, an opportunity was encountered in the field of education to investigate the possibilities of a multidisciplinary dialogue. During the process of Brazilian children's literacy development (still referred as encoding and decoding in reading and writing), one of the main teaching tools is ephemeral teaching materials, made by the teachers themselves and used in the classroom. Although such materials are intended to stimulate children to search and generate knowledge, it is still common to use foreign graphic references, massified or removed from their everyday realities. Thus, this article aims to provoke reflections on the role of Design/Education, proposing an investigation of educational practices that encourage learners to do more than just read words, but rather to read the world around them and recognize their own culture as educational content, which may be studied though in-and out-of-school experiences.

\section{Introdução}

O Ensino Fundamental é, no Brasil, o ciclo mais extenso da Educação Básica e caracteriza-se como um período de grandes transformações e descobertas para a criança. Ao longo dos nove anos de aprendizado (dos 6 aos 14 anos), os estudantes passam por um dos processos mais importantes das suas vidas escolares: a alfabetização.

Embora concordemos que aprender a ler e a escrever, bem como interpretar as informações assimiladas, é um dos grandes divisores de águas do período estudantil, acreditamos que o conceito de alfabetização seja muito mais amplo do que simplesmente ler, escrever e compreender um texto escrito. Para Bissoli (2006), esse processo começa no início da vida humana, quando as crianças entram em contato com um grande universo de manifestações gráficas e empenham-se para compreendê-las, mesmo antes de serem alfabetizadas. Para ela,

Anais do 8 CIDI e 8 CONGIC

Guilherme Santa Rosa; Cristina Portugal (orgs.)

Sociedade Brasileira de Design da Informação - SBDI

Natal | Brasil | 2017

ISBN 978-85-212-1305-5
Proceedings of the $8^{\text {th }}$ CIDI and $8^{\text {th }}$ CONGIC

Guilherme Santa Rosa; Cristina Portugal (orgs.)

Sociedade Brasileira de Design da Informação - SBDI

Natal | Brazil | 2017

ISBN 978-85-212-1305-5 
esse esforço em atribuir significados às mensagens visuais pode ser considerado uma forma de leitura.

Assim, a autora (Bissoli, 2006) elucida que o processo de alfabetização engloba também a compreensão de códigos não linguísticos, encontrados em diferentes suportes que podem potencializar o processo de aprendizagem infantil. Isso se dá por meio da exploração dos códigos visuais dispostos em mídias e artefatos que fazem parte do universo visual externo à sala de aula.

Nesse sentido, encontramos no tecido urbano, especialmente nas grandes cidades, um ambiente formado por variados tipos de manifestações gráficas, ricas em cores, formas, texturas, imagens e letras do alfabeto, dispostas em composições visuais diversas. Tal cenário é descrito por Hennes \& Coutinho (2014) como uma biblioteca de experiências táteis e visuais, democrática, disponível e gratuita.

Tais manifestações gráficas locais formam complexos sistemas de informação urbana, que coexistem numa dada estrutura espacial, organizada de acordo com contextos socioculturais diversos. Mas há um tipo singular de artefato que, devido às suas peculiaridades gráficas e semânticas, encontra-se enraizada e legitimada na identidade dos seus habitantes. São os letreiros populares, compostos por elementos verbais, pictóricos e/ou esquemáticos da linguagem gráfica (LG) de natureza vernacular, que continuam chamando a atenção pela riqueza iconográfica e simbólica de seus elementos (figura 01).

Figura 1: Painel com recortes de elementos verbais e pictóricos de letreiros populares registrados em Recife (PE) (usado com a permissão de Hennes \& Coutinho, 2014).

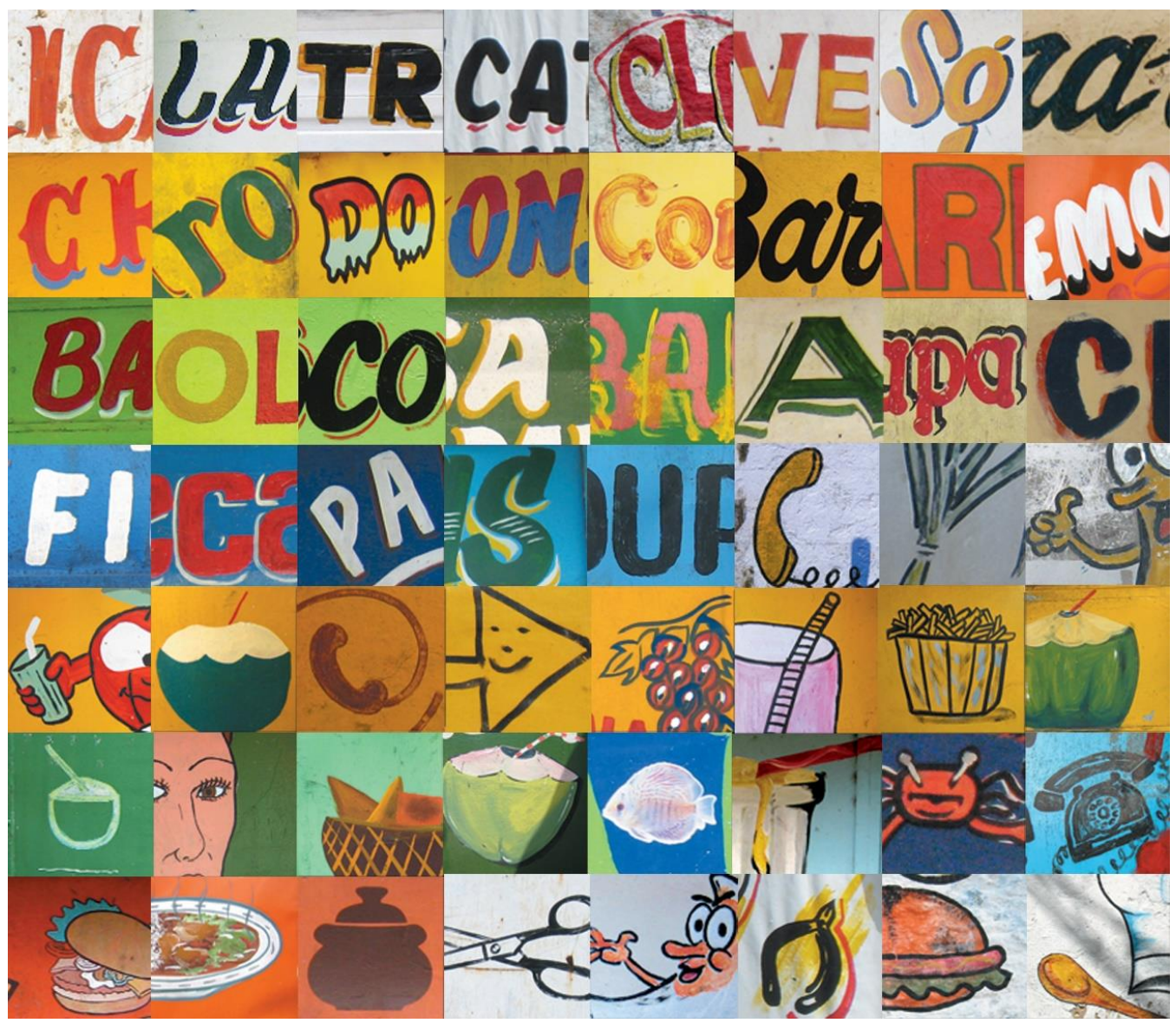

Para Hennes (2012), é possível entender os letreiros populares como manifestações gráficas urbanas que mantêm, em sua essência, características próprias da cultura popular. São confeccionadas artesanalmente, em processos manuais intuitivos ou com a utilização de técnicas passadas de geração em geração ou do mestre ao aprendiz. Embora exista uma tendência de substituição desses letreiros populares por artefatos impressos, a literatura atual sobre o tema ressalta que a prática ainda está longe de ser extinta. Isso ocorre devido ao caráter democrático de produção, já que, 'potencialmente, qualquer pessoa, com mínima 
habilidade artística, é capaz de produzi-los, sob um baixo custo' (Hennes \& Coutinho, 2014: 03).

De acordo com pesquisas no campo do Design da Informação, as quais tomaram esses elementos como objeto de estudo, autores como Finizola (2010; 2015) e Hennes (2012) aludem que tais inscrições são parte importante da cultura material e imaterial popular brasileira, e têm sua maior incidência em cidades da região Nordeste. Elas permeiam o repertório e a memória gráfica das pessoas de todas as camadas sociais, por refletirem a alma da região, com suas cores, seus grafismos e seus discursos. Assim, no que tange sua importância enquanto objeto de estudo para o campo do Design, Finizola (2015) afirma que

[...] o tema da gráfica popular é estudado com abordagens diversas: como objeto estético e tipográfico; elemento de comunicação da paisagem urbana; objeto representativo da nossa memória gráfica popular; ou ainda como uma prática social, uma tradição viva que deve ser preservada e renovada. (Finizola, 2015: 60)

Portanto, faz sentido pensar que esses elementos, capazes de nos situar no tempo e no espaço, também possam contribuir na geração de conteúdos multidisciplinares ao articular os campos da cultura material e imaterial, da identidade e da memória gráfica de uma determinada comunidade com pesquisas envolvendo Design/Educação.

\section{Alfabetização e letramento: ampliação de significados na contemporaneidade}

Embora o Plano Nacional de Educação brasileiro ainda utilize o termo alfabetização, ao apresentar os objetivos educativos para o ensino fundamental nacional entre 2014 e 2024, o entendimento sobre como se dá o processo de alfabetização vem sendo amplamente discutido no campo da Educação. No próprio documento (PNE 2014-2024), há um importante esclarecimento:

A alfabetização hoje não pode mais ser considerada uma (de)codificação mecânica de letras e sílabas; ela deve ser entendida em relação à efetiva participação da criança nas práticas de letramento às quais se encontra exposta, dentro e fora da escola. Assim, torna-se necessário tomar os usos e as funções da língua escrita com base na elaboração de atividades significativas de leitura e escrita nos contextos em que vivem as crianças (PNE 2014-2024, 2014: 85-86).

Sobre esse aspecto, Santi (2014) explica que as novas reflexões acerca da alfabetização tratam desse processo sob uma ótica cultural, no qual a criança passa, não apenas a dominar a lectoescrita, mas a relacionar esse aprendizado ao contexto social no qual está inserida. Assim, esse novo entendimento sobre a alfabetização implica mudanças no que se refere ao ensino da leitura e da escrita nas escolas, e a adoção de outro vocábulo capaz de melhor representar esse momento da vida escolar: o letramento - termo que adotaremos a partir de agora.

A autora (Santi, 2014) elucida que, para um processo de letramento eficiente, a criança precisa interagir com outros indivíduos que tangenciam sua vida cotidiana, além de ter acesso a informações de naturezas diversas, ser capaz de produzir seus próprios textos e atuar ativamente diante do conhecimento que estão sendo preparadas para receber em sala de aula.

Segundo Duarte et al. (2008), algumas práticas educativas tradicionais não permitem trocas de conhecimento entre mestres e aprendizes, haja vista que, até pouco tempo, era usual que crianças pensassem que 'aquilo que existe para conhecer já foi estabelecido, como um conjunto de coisas fechado que não podem se modificar' (Duarte et al., 2008: 05). Nessas situações, esses indivíduos se comportavam como meros espectadores ou receptores mecânicos daquilo que o professor ensinava, especialmente em práticas de letramento que envolve a junção de sílabas simples, memorização de sons, decifração e cópia.

No século XXI, palco de tantas mudanças nas mais diversas relações sociais humanas, essa realidade está se modificando gradativamente, por meio de iniciativas que buscam integrar temáticas cotidianas das crianças e referências culturais dos seus locais de origem ao ensino de matérias básicas, como português e matemática. Um bom exemplo dessas iniciativas vem sendo implantada na Escola Arraial Novo de Bom Jesus, situada na região metropolitana da cidade do Recife (PE). Segundo informações disponibilizadas na página virtual da TV Escola - canal de TV vinculado ao Ministério da Educação brasileiro -, a supracitada escola é pública e, desde 2014 , desenvolve um projeto de letramento infantil em 
torno da construção da identidade pessoal, familiar e comunitária dos estudantes.

Em uma matéria que girou em torno do tema da alfabetização (TV Escola, 2014), educadoras dessa escola explicam que uma das metodologias de ensino é pautada na eleição de eixos temáticos de referência cultural, como guia para as práticas educativas dos períodos letivos. Assim, personalidades como Luiz Gonzaga, músico de grande reconhecimento na cultura nordestina por difundir ritmos, costumes, vocábulos, vestimentas, cenários e modos de vida do povo sertanejo, são trabalhadas em sala de aula, ampliando o repertório cultural dos estudantes ao mesmo tempo em que contribuem para o desenvolvimento da lectoescrita.

No entanto, embora se reconheçam as transformações fundamentais que o campo da Educação Básica brasileira vem passando nas últimas décadas, pesquisas que articulam Design e Educação demonstram que ainda há um vasto território inexplorado - especialmente relacionado à produção de materiais didáticos efêmeros pelos professores do ensino fundamental -, passível de investigação e desenvolvimento.

\section{Produção de materiais didáticos por professores do ensino fundamental: ferramentas importantes no processo de letramento infantil}

Uma das grandes problemáticas relacionadas à produção de materiais didáticos, pelo professor, está na negligência com que essa prática é tratada no campo da Educação. Para Cadena \& Coutinho (2015), a falta de discussões sobre novas ferramentas e conteúdos leva-os a repetição das técnicas de ensino, optando-se, quase sempre, pelas alternativas tradicionais. Assim, os debates acerca da produção de artefatos didáticos efêmeros, pelos professores, são tão necessários quanto urgentes na medida em que os aproxima 'das linguagens e possibilidades que os alunos vivenciam e demandam contemporaneamente na vivência escolar e extraescolar' (Cadena \& Coutinho, 2015: 08).

Considerando a relevância da figura dos professores em sala de aula, enquanto principais mediadores e articuladores do processo de ensino-aprendizagem, Cadena \& Coutinho (2015), ressaltam a importância de se inserir o estudo da linguagem gráfica na formação dos educadores. Para as autoras (Cadena \& Coutinho, 2015), trata-se de um conteúdo imprescindível para uma formação profissional mais condizente com as necessidades e práticas educacionais contemporâneas, que exigem o uso e criação de mensagens visuais complexas, do ponto de vista sociocultural.

Abordando especificamente as práticas educativas voltadas para o letramento infantil, é comum encontrar materiais didáticos efêmeros, produzidos pelos próprios professores, a partir de técnicas tradicionais de ensino do alfabeto, sem referências culturais locais ou expressivas para o contexto social da criança. Assim, os elementos da linguagem gráfica utilizados (verbais, pictóricos e esquemáticos) são escolhidos sem grandes reflexões acerca das suas propriedades morfológicas e caráter informativo, sendo essas decisões tomadas, quase sempre, de forma empírica pelos educadores.

A partir de uma observação nessa perspectiva, constatou-se que, frequentemente, são empregadas, como conteúdo didático, referências pertencentes a veículos de comunicação de massa estrangeiros, considerados atraentes para o público infantil, do ponto de vista do professor. É o caso dos painéis gráficos intitulados calendário e cantinho da linguagem (figura 02), decorados com personagens da Disney, confeccionados por uma professora do ensino fundamental de uma escola da rede particular de ensino da cidade de Moreno (PE). Embora se reconheça a existência de um senso estético coerente e agradável na composição de cores e na diagramação dos elementos gráficos, a falta de diálogo desses artefatos com o contexto social local reprime a ampliação do repertório imagético das crianças, bem como a valorização de referências culturais locais como conteúdos educativos. 


\section{CIDI 2017

Figura 02: Painéis utilizados como materiais didáticos efêmeros em sala de aula, decorados com personagens da Disney, numa escola da rede particular de ensino de Moreno (PE). (Fonte: imagem extraída do blog Ideia Criativa, usada com permissão de Gi Barbosa e Davi Barbosa).
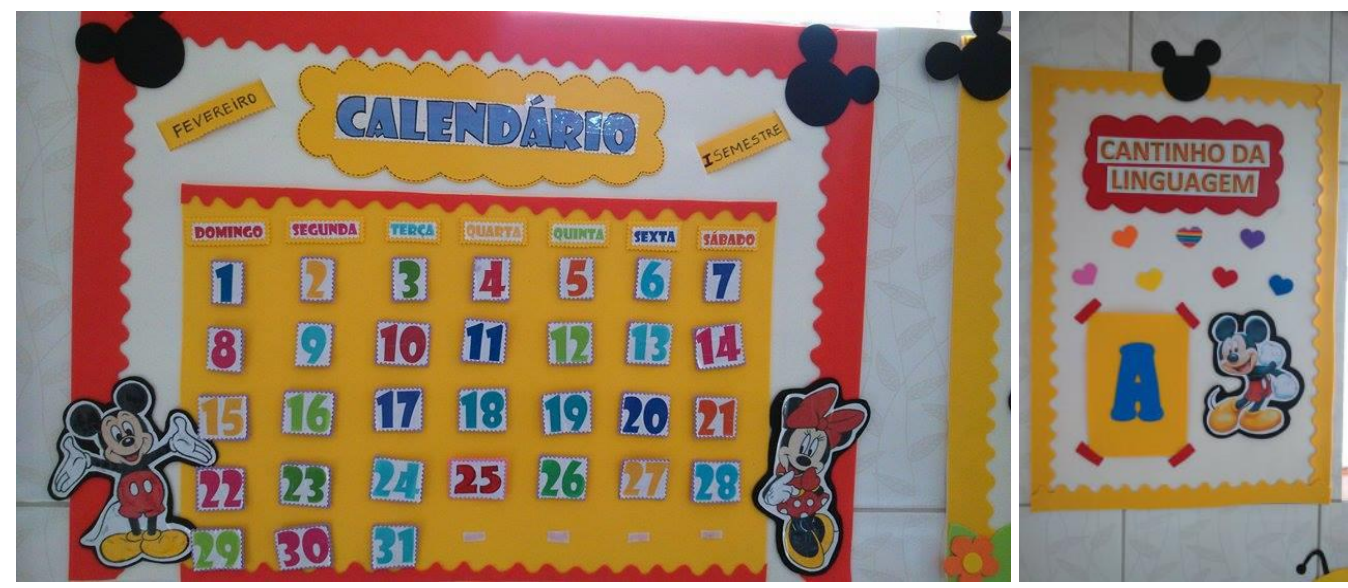

Um dos materiais didáticos tradicionais para letramento infantil mais adotado nas salas de aula brasileiras é o chamado alfabeto ilustrado ${ }^{1}$. Nesse material, as conexões entre elementos verbais (letras) e pictóricos (ilustrações) acontecem, quase sempre, utilizando-se referências de um repertório gráfico pouco variado, com estilos de representação gráfica sem valor semântico claro e fontes tipográficas escolhidas aleatoriamente, sem considerar aspectos como pregnância da forma, legibilidade e hierarquia da informação.

Na Escola Arraial Novo de Bom Jesus, de Recife (PE), citada anteriormente como um bom exemplo de instituição que vem implantando iniciativas voltadas às renovações das práticas escolares, o alfabeto ilustrado (figura 03) é um dos materiais didáticos efêmeros utilizados em sala de aula que permanece deslocado quanto aos significados culturais dos elementos gráficos utilizados.

Figura 03: Alfabeto ilustrado, utilizado como ferramenta de ensino-aprendizagem de letramento na Escola Arraial Novo de Bom Jesus, em Recife (PE). (imagem extraída de matéria televisiva veiculada publicamente pela TV Escola em 2014).

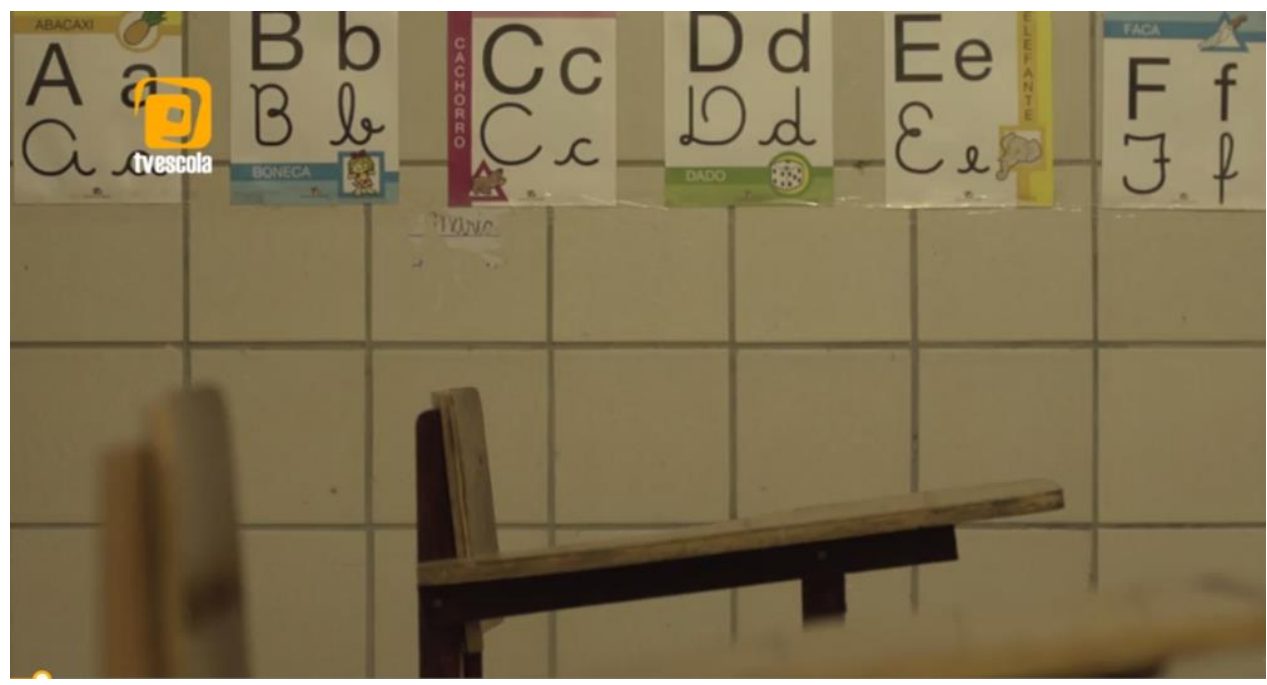

Nesse exemplo, as letras são dispostas em duas fontes tipográficas distintas - sem serifa (parte superior) e cursiva (parte inferior) -, com demonstração dos caracteres em caixa alta e caixa baixa. Embora essa diversidade seja interessante, do ponto de vista da ampliação do repertório tipográfico da criança, a composição dos elementos nos cartazes apresenta vários problemas: pouca ênfase nos elementos pictóricos (pequenos para serem observados a

\footnotetext{
$1 \mathrm{O}$ alfabeto ilustrado, termo utilizado pelos educadores, consiste na apresentação de letras do alfabeto dispostas em cartazes posicionados em sequência alfabética, nos quais também são associadas figuras que tenham na letra inicial do seu nome, correspondência ao caractere apresentado no cartaz.
} 
distância), algumas palavras aparecem dispostas na vertical (dificultando a leitura por não seguir o padrão horizontal, da esquerda para direita), além de não apresentar nenhuma característica de referência sociocultural nos artefatos - seja no significado dos elementos ou no estilo das representações.

Ainda que o alfabeto ilustrado seja largamente utilizado nas escolas brasileiras, por ser de configuração simples e objetiva, não existe um padrão gráfico disponibilizado ou orientado pelo Ministério da Educação (MEC), acerca das escolhas dos elementos, materiais, diagramação e outras especificações, como tamanho mínimo/máximo dos cartazes. Sendo assim, os professores acabam arcando com a responsabilidade de produzir esses artefatos fisicamente, adicionando essa demanda à carga horária de trabalho, normalmente, já bastante elevada.

A partir de itens disponibilizados pelas escolas - como cola branca, papéis coloridos, pincéis hidrocores, materiais emborrachados (Etil Vinílico Acetato - E.V.A.), etc. - educadores aplicam técnicas criativas na combinação de materiais e processos de produção gráfica (muitas vezes artesanais), gerando uma grande diversidade de configurações para esses artefatos.

O fato de muitos não possuírem tempo disponível para confecção de materiais didáticos efêmeros ou não terem conhecimentos básicos de diagramação, composição gráfica ou produção gráfica, acabou gerando a necessidade de se buscar referências, moldes e gabaritos, junto a outros educadores do ensino fundamental, que têm as mesmas demandas e, por isso, também confeccionam materiais didáticos similares.

Portanto, a necessidade de trocas de conhecimento sobre práticas educativas, associada à vontade de divulgação dos trabalhos desenvolvidos em sala de aula culminaram no surgimento de blogs virtuais, alimentados por professores do ensino fundamental. Essas páginas da web têm o intuito de estabelecer um diálogo direto com outros educadores, além de funcionar como um banco de dados, no qual são disponibilizados modelos de artefatos gráficos passíveis de serem copiados artesanalmente ou baixados para reprodução impressa. Dentre os blogs encontrados no mapeamento realizado utilizando as palavras 'blog ensino fundamental' e 'modelos de materiais didáticos', destacam-se o blog Ideia Criativa, alimentado pelos educadores Gi Barbosa e Davi Barbosa, e o Meu Cantinho de Ideias, da educadora Glauce Iraniele.

Em ambas as páginas virtuais é possível encontrar exemplos de alfabetos ilustrados, apresentados como referência, que podem ser copiados ou reproduzidos gratuitamente, como o Alfabeto llustrado Estrela Cadente (figura 04) e o alfabeto ilustrado em E.V.A, confeccionado artesanalmente (figura 05).

Figura 04: Alfabeto ilustrado Estrela Cadente, do blog Ideia Criativa. (Fonte: imagem extraída do blog Ideia Criativa em 2017, usada com permissão dos educadores Gi Barbosa e Davi Barbosa)
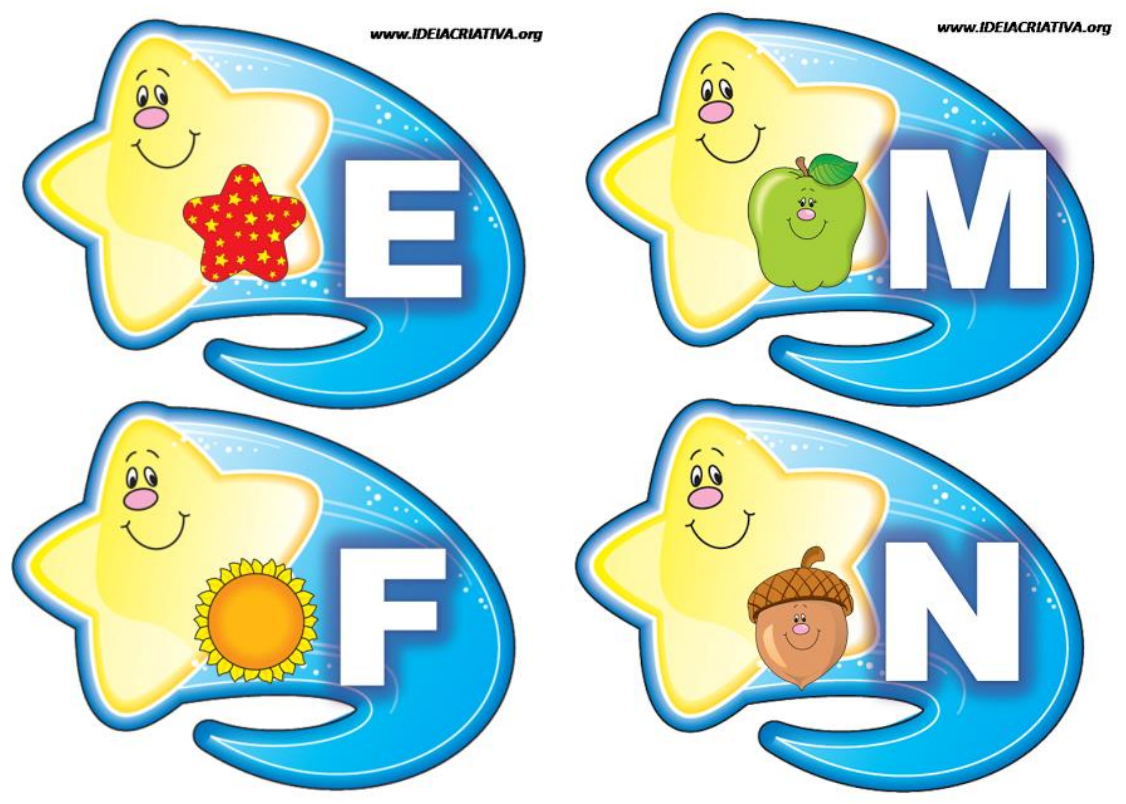

Anais do 8ํㅡㄹ Congresso Internacional de Design da Informação | CIDI 2017

Proceedings of the $8^{\text {th }}$ Information Design International Conference | CIDI 2017 
Figura 05: Alfabeto ilustrado confeccionado artesanalmente em E.V.A. (fonte: imagem extraída do blog Meu Cantinho de Ideias, usada com permissão da professora da rede municipal de ensino de Teresópolis (RJ), Glauce Iraniele).

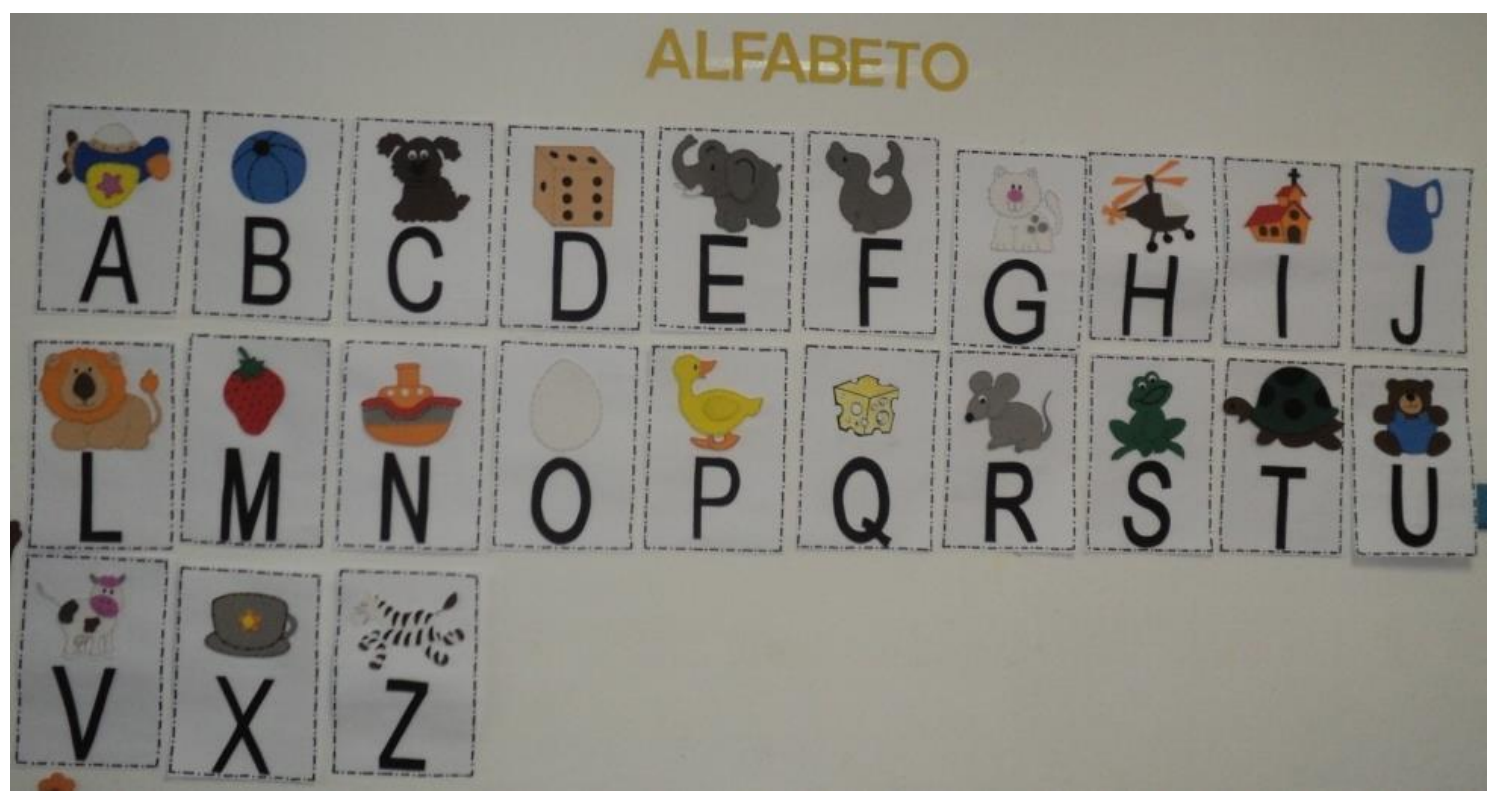

Nesses exemplos, é possível verificar que as figuras têm um peso considerável na composição, desempenhando tanto a função decorativa (no caso do elemento estrela cadente) como função informativa (no caso dos elementos pictóricos ilustrativos associados aos caracteres alfabéticos). Além disso, os elementos verbais constam em apenas um estilo de fonte tipográfica - sem serifa - com letras em caixa alta.

Ainda que se possa reconhecer que tais conteúdos sejam interessantes, no sentido de possibilitar também a aquisição de conhecimentos gerais e estrangeiros pelos alunos, a não inclusão de referências e cenas do dia a dia desses estudantes pode ser vista sob uma ótica deficitária, já que não possibilita o reconhecimento do contexto sociocultural a sua volta como conteúdo educativo, passível de ser trabalhado em sala de aula (Guerra \& Gusmão, 2004).

A partir de uma reflexão sobre tais aspectos, o estudo desenvolvido pelo professor Richard Huerta (2010), docente na área de Educação Artística da Universidade de Valencia (Espanha) e diretor do Instituto de Creatividad e Innovaciones Educativas, é um bom exemplo de articulação entre conteúdos educativos e referências externas à sala de aula. Para ele (Huerta, 2010), o estudo das letras e de outros elementos gráficos encontrados no cenário urbano, permite indagamentos sobre como os profissionais da educação poderiam contribuir para a criação de espaços de ensino que visassem motivar, ensinar e ampliar os repertórios imagéticos e socioculturais de crianças.

Huerta (2010) alude em seu artigo I Like Cities; Do You Like Letters? Introducing Urban Typography in Art Education, que as ruas das grandes cidades estão repletas de sinalizações gráficas, em que as letras e os símbolos ocupam um lugar central, não apenas pelo sentido dos enunciados, mas pela forma gráfica que apresentam.

Para Huerta (2010), as fontes encontradas no espaço urbano ajudam-nos a reinterpretar o patrimônio cultural da cidade em que vivemos, e que a utilização de tipografas e figuras de referência local permite, aos educadores, a utilização de recursos gráficos com um poder de articulação muito maior do que os elementos sem essa carga simbólica.

Portanto, estudos sobre os elementos da linguagem gráfica, aplicados ao contexto educativo, levam-nos a crer que as crianças, em fase de letramento, percebem e dialogam com os estímulos visuais diversos, de forma particular. Mesmo que ainda não saibam ler e escrever plenamente, esses estudantes reconhecem as diferenças morfológicas dos elementos e são capazes de perceber os discursos semânticos intrínsecos a eles. 


\section{0 design da informação e a construção da identidade sociocultural infantil a partir de práticas educativas de letramento: potencialidades observadas nos letreiros populares do Recife}

O design da informação, área intrinsecamente ligada ao design gráfico, é responsável pela investigação dos aspectos sintáticos, semânticos e pragmáticos dos variados sistemas informacionais disponíveis em nosso entorno. De acordo com Simlinger (2007), coordenador do International Institute for Information Design - IIID, o design da informação está tanto associado ao planejamento e formatação do conteúdo de uma mensagem, quanto à sua própria definição no âmbito em que é apresentado. Assim, julga-se papel do designer propor um diálogo entre as necessidades informacionais identificadas na mensagem, e às necessidades dos usuários ao interpretá-las (Simlinger, 2007: 8).

Souza et al. (2016), ao investigarem alternativas epistemológicas contemporâneas para o design da informação, ponderam que a própria forma da mensagem é considerada componente essencial do seu conteúdo, já que desempenha função fundamental nas trocas comunicacionais entre emissores e receptores das mensagens. Sobre esse aspecto, os autores sugerem que a forma 'não deve ser entendida como um desfoque do conteúdo, mas um modo de estruturar a realidade, tornando a atividade do designer um processo ativo de enformar o mundo' (Souza et al., 2016: 108).

Ao interferir na mensagem por meio da sua contextualização, planejamento e organização, o designer não apenas facilita o entendimento do conteúdo, mas atua como coautor, encontrando diferentes maneiras de interpretar a mensagem, e criando 'novas narrativas e experiências gráficas' fundamentais na comunicação com o usuário (Camargo, 2011: 128).

Ponderando que as trocas comunicacionais acontecem a partir do entendimento das identidades culturais dos indivíduos e dos códigos que regem as várias linguagens inteligíveis, é possível afirmar que o aspecto informacional gráfico das mensagens pode exercer um impacto significativo no entendimento, assimilação e engajamento dos usuários, frente a um dado conteúdo. Quando se trata de um indivíduo no início da vida, em estágio de formação de seu repertório visual e das suas referências culturais, esse aspecto torna-se ainda mais expressivo.

Ao investigar as características morfológicas e semânticas de letreiros populares do Recife, especialmente os elementos verbais e pictóricos presentes, Hennes (2012) encontrou aspectos relevantes que fazem parte do universo gráfico popular da cidade. Do ponto de vista morfológico, destacam-se: (a) a predominância de letreiros confeccionados sem o auxílio de fôrmas ou moldes, ressaltando o caráter original das inscrições pintadas e decoradas à mão livre; (b) a possibilidade de identificar padrões gráficos, apesar da variada gama de elementos, cores, decorações e outros componentes visuais; (c) o caráter autoral dos desenhos de letras e figuras, com base na criatividade e habilidade dos letristas especialistas e não especialistas; (d) a diversidade das representações pictóricas - ora com grande riqueza de detalhes, ora sintáticas e minimalistas; (e) o caráter lúdico e/ou cômico dos muitos enunciados, explicitado tanto nos elementos verbais quanto nos pictóricos; e (f) as referências valorativas/semânticas que as composições gráficas podem imputar ao produto comercializado ou serviço prestado, como mostra o exemplo do letreiro Cia do Guaraná (figura 06). 


\section{CIDI 2017

Figura 06. Letreiro Cia do Guaraná, registrado no Mercado de Casa Amarela, em Recife (PE), no ano de 2011 (usado com a permissão de Hennes).

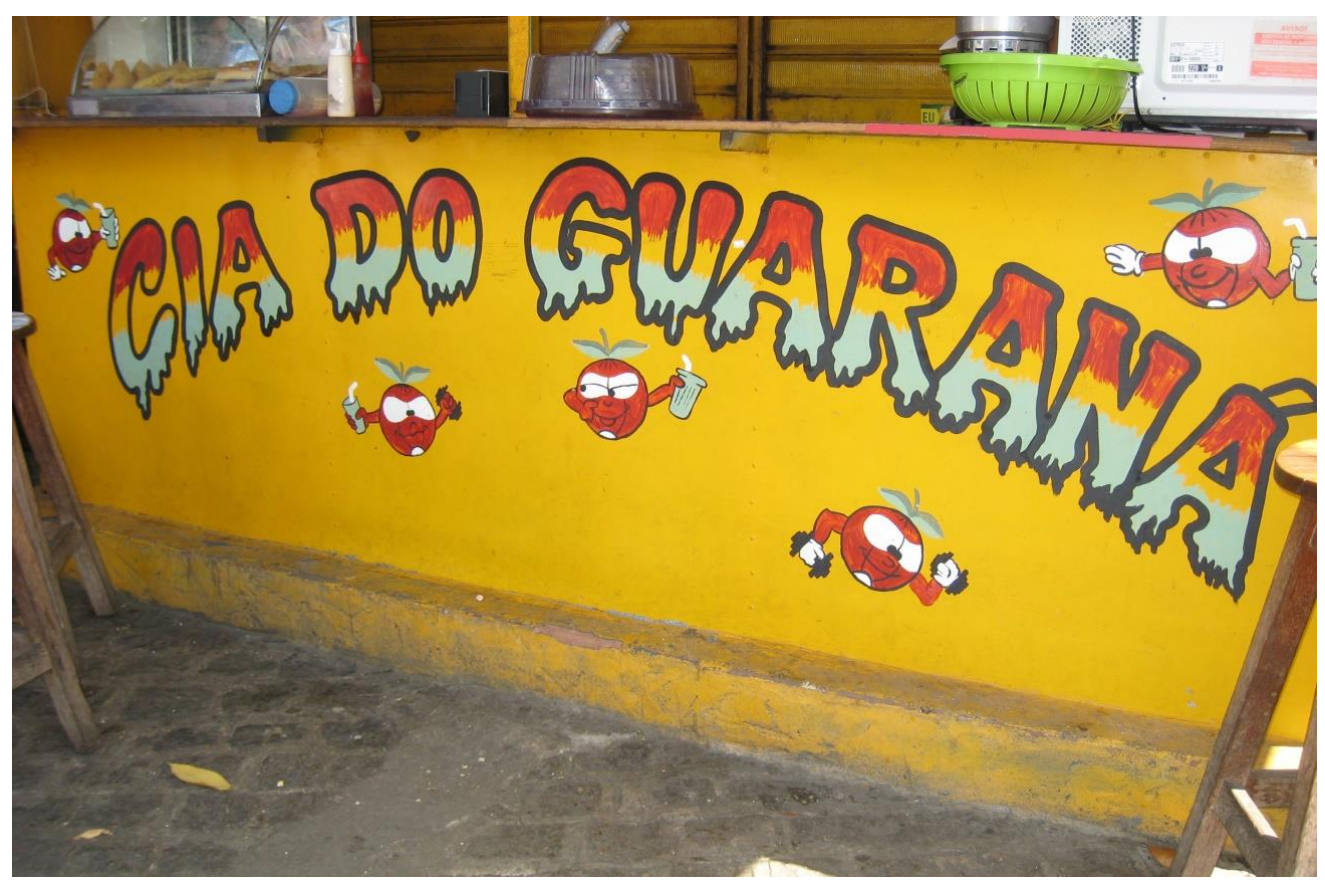

Do ponto de vista semântico, Hennes (2012) observa, nessa composição, que as letras parecem derreter com o calor tipicamente recifense e as frutas de guaraná praticam exercícios físicos, destacando a característica saudável/fitness do produto e reforçando a relação entre o sentido da mensagem textual e a forma gráfica do enunciado.

Todos esses aspectos investigados e validados pela pesquisa permitem associações com outros setores do contexto local, como a irreverência e ludicidade presentes no carnaval e no folclore, a autenticidade da linguagem popular e as características formais presentes em outros artefatos da cultura material, como construções coloniais multicoloridas e a originalidade do artesanato. Todas essas conexões contribuem para o fortalecimento da identidade cultural recifense e para a ampliação do repertório visual dos seus habitantes e visitantes.

Ao imaginar possíveis diálogos entre a temática dos artefatos gráficos vernaculares urbanos e o contexto escolar de ensino-aprendizagem, verifica-se que a própria técnica de letramento chamada de alfabeto ilustrado, já mencionado, poderia suscitar considerações passíveis de utilização de referências gráficas locais nas representações das letras do alfabeto.

A partir de um breve mapeamento no banco de imagens que compôs o corpus da pesquisa sobre Letreiros Populares do Recife (Hennes, 2012), uma série de elementos verbais e pictóricos plurais em suas características gráficas (formas, cores, decorações texturas, etc.) foi encontrada (figuras 07 e 08). Em meio a tantos estímulos visuais e sensoriais, o destaque dáse na figura 07 , que reúne somente elementos pictóricos, os quais apresentam na inicial de seus nomes, a letra "C". 


\section{CIDI 2017 ind}

Figura 07. Elementos pictóricos, extraídos de fotografias de letreiros populares da cidade do Recife, representativos da letra "C": coco (sete representações gráficas diferentes); coxinha (três representações gráficas diferentes); confeito; chapéu e colher; copo e canudo (usada com a permissão de Hennes \& Coutinho, 2014).
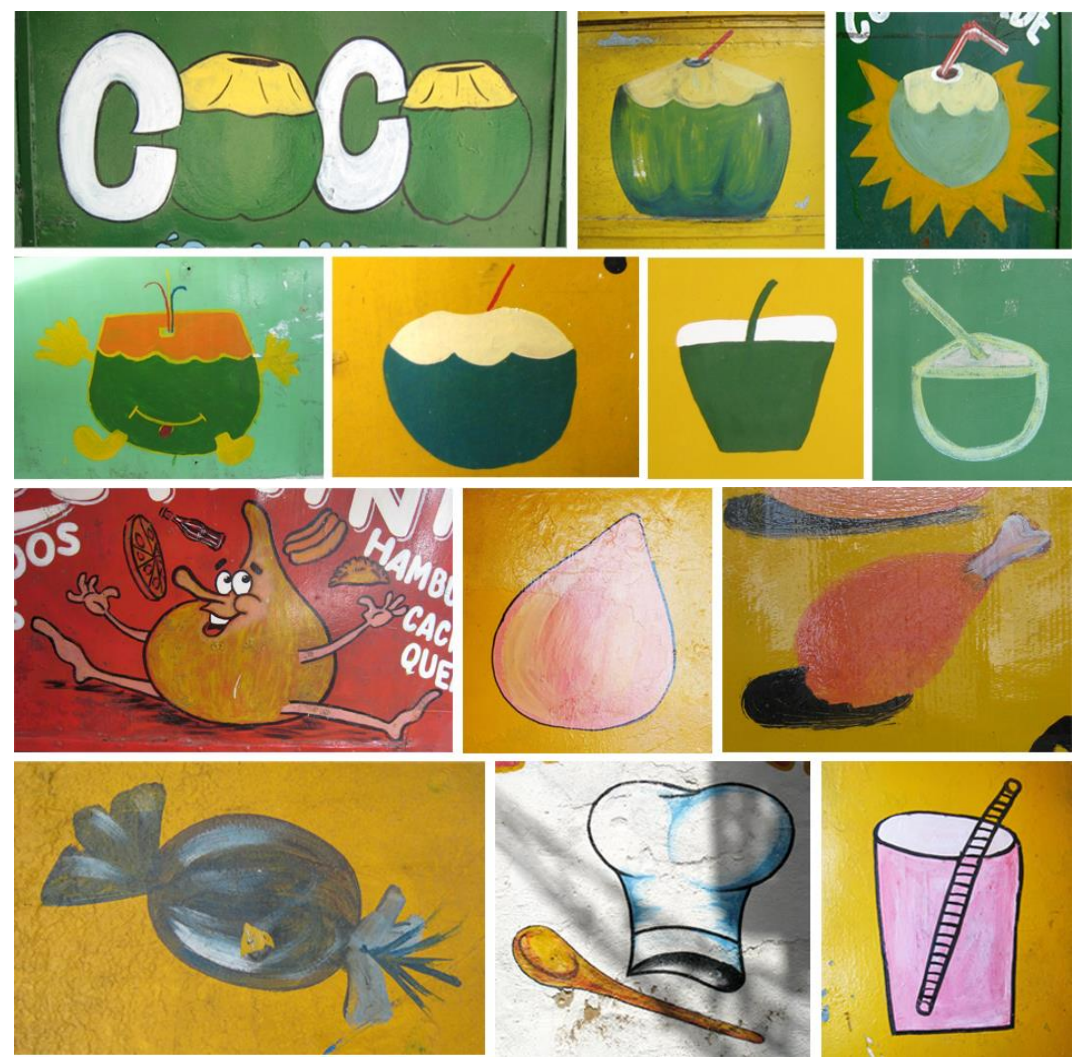

Figura 08. Elementos verbais, extraídos de fotografias de letreiros populares do Recife (usado com a permissão de Hennes, 2012)

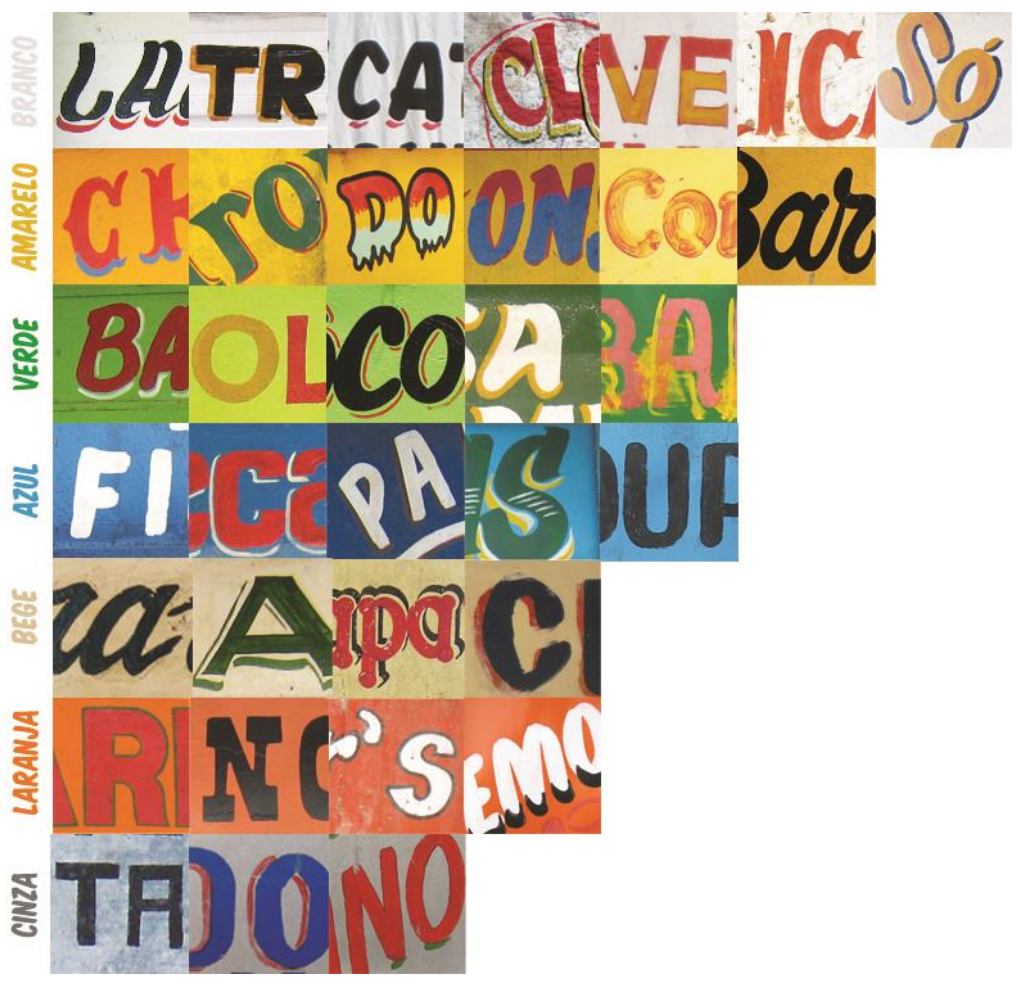

${ }^{2}$ Termo faz parte do vocábulo regional recifense para designar: bala, bombom, etc. 
Sendo assim, adotando a concepção de Huerta (2010) e Hennes \& Coutinho (2014) acerca das possibilidades que as ruas das cidades oferecem e podem ser observadas sob a ótica de um museu ao ar livre, propõe-se a diminuição das barreiras sociológicas atreladas ao ambiente urbano, já que este se revela um local de grande diversidade visual e cultural, sem restrições estéticas.

\section{Considerações finais}

Articulando setores sociais considerados prioritários nas ações brasileiras de ensino, pesquisa e extensão - Educação e Cultura -, o estudo aqui apresentado tangenciou tanto o universo dos materiais didáticos efêmeros, essenciais às práticas de ensino-aprendizagem durante a fase de letramento, quanto o estudo da linguagem gráfica em contextos socioculturais locais, tomando como referência os letreiros populares presentes na cidade do Recife.

Devido à variedade morfológica dos elementos gráficos apresentados, e sua relevância enquanto artefatos culturais importantes para a construção e valorização de uma memória gráfica local, esse estudo se propôs a provocar questionamentos acerca de novas possibilidades de inserção de elementos da memória gráfica de comunidades locais em contextos educativos.

Tomando como foco o processo de letramento infantil, faz sentido imaginar que a inserção desses conteúdos nas práticas de ensino-aprendizagem em sala de aula pode contribuir para $o$ desenvolvimento da cultura visual infantil, potencializar o aprendizado e impulsionar o engajamento das crianças para a leitura e a interpretação de mensagens dentro e fora da escola, contextualizando-as social e culturalmente e incentivando o desenvolvimento de um pensamento crítico.

Nesse sentido, acredita-se que muitas estratégias podem ser extraídas dos elementos imagéticos e textuais do tecido urbano, com o objetivo de comunicar valores estéticos e culturais às crianças. Isso é possível na medida em que compreendemos que qualquer criança que realize algum tipo de trabalho gráfico terá que tomar decisões acerca da forma das letras, do tipo de representação pictórica e da composição visual desse conteúdo.

As reflexões realizadas nesse trabalho ainda dialogam com algumas iniciativas que vêm sendo desenvolvidas no campo do Design/Educação, com destaque para a produção vinculada ao Departamento de Design da Universidade Federal de Pernambuco. Dentre os principais grupos de pesquisa, destacam-se o InfoDesign que apresenta, como uma de suas propostas, a investigação das práticas educacionais sob a ótica do Design da Informação, e o RIDE - Rede Internacional Design/Educação, que trata da contextualização, planejamento e produção de interfaces gráficas da informação, assim como a formação e aquisição da informação por professores e estudantes.

\section{Referências}

BISSOLI, L. S. 2006. Leitura de imagens: as concepções dos professores de educação infantil. Dissertação de Mestrado não publicada. Universidade Estadual Paulista. Programa de PósGraduação em Educação: Rio Claro.

CADENA, R.; COUTINHO, S. G. 2015. Investigando projeções: critérios para a análise de apresentações digitais de slides. In: C. G. Spinillo; L. M. Fadel; V. T. Souto; T. B. P. Silva \& R. J. Camara (Eds). 7th Information Design International Conference. São Paulo: Blucher, 2015. p. 1276-1282.

CAMARGO, I. P. 2011. O departamento de Design Gráfico da Cranbrook Academy of Art (1971-1995): novos caminhos para o design. Dissertação de mestrado não publicada. Faculdade de Arquitetura e Urbanismo - FAU/USP. São Paulo. 
DUARTE, K.; ROSSI, K.; RODRIGUES, F. 2008. O processo de alfabetização da criança segundo Emilia Ferreiro. In: Revista Científica Eletrônica de Pedagogia, Garça, SP, ano 6, n. 11. <http://www.revista.inf.br/pedagogia/pages/artigos/edic11-anovi-art02.pdf>. 30/04/2017.

FINIZOLA, F. 2010. Panorama tipográfico dos letreiramentos populares: um estudo de caso na cidade do Recife. Dissertação de mestrado não publicada. Departamento de Design. Universidade Federal de Pernambuco, Recife.

FINIZOLA, F. 2015. A tradição do letreiramento popular em Pernambuco: uma investigação acerca de suas origens, forma e prática. Tese de doutorado não publicada Departamento de Design. Universidade Federal de Pernambuco, Recife.

GUERRA, R. A. T.; GUSMÃO, C. R. C. 2004. A produção de material paradidático para implementação da educação ambiental em escoas públicas. João Pessoa, PB: Editora da UFPA.

HENNES, M. 2012. Letreiros populares do Recife: uma análise dos seus aspectos semânticos e morfológicos. Dissertação de mestrado não publicada. Departamento de Design. Universidade Federal de Pernambuco, Recife.

HENNES, M.; COUTINHO, S. G. 2014. Popular lettering in Recife: an analysis of its pictorial elements. In: Coutinho, Solange G.; Moura, Monica; Campello, Silvio Barreto; Cadena, Renata A.; Almeida, Swanne (Orgs.). Proceedings of the 6th Information Design International Conference. São Paulo: Blucher.

HUERTA, R. 2010. I like cities; Do you like letters? Introducing urban typography in art education. International Journal of Art \& Design Education, vol. 29, n. 1, p. 72-81.

IRANIELE, G. 2011. Alfabeto llustrado. Meu Cantinho de Ideias (blog). <http://glauceiraniele.blogspot.com.br/2011/03/alfabeto-ilustrado.html> 28.04.2017.

BARBOSA, G.; BARBOSA, D. 2015. Decoração para Sala de Aula Mickey e Minnie Espaço do Educador Ideia Criativa. IDEIA CRIATIVA (blog). <http://www.ideiacriativa.org/2015/01/decoracao-para-sala-de-aula-mickey-e.html> 28.04.2017.

PLANO NACIONAL DE EDUCAÇÃO (PNE). Plano Nacional de Educação 2014-2024: Lei nº 13.005, de 25 de junho de 2014. Brasília: Câmara dos Deputados, Edições Câmara, 2014 86 p. (Série legislação; n. 125). < https://goo.gl/c6KxQO>. 05.05.2017.

OLIVEIRA, J. O. A. D. B. E.; JORENTE, M. J. V. 2015. Design da informação e ciência da informação: uma aproximação possível. Encontro Nacional de Pesquisa em Ciência da Informação, João Pessoa, v. 16. <https://goo.gl/5DLLBQ> 10.04.2017.

SANTI, P. A. 2014. Alfabetização e letramento nos anos iniciais do ensino fundamental. Monografia. Curso de Pedagogia. Universidade Regional do Noroeste do Estado do Rio Grande do Sul, Unijuí.

SIMLINGER, P. 2007. Information Design: Core Competencies. What information designers know and can do. <http://www.iiid.net/PDFs/idxPublication.pdf>. 12.04.2017.

SOUZA, E. 2007. O uso de recursos didáticos no ensino escolar. Arq Mudi. 2007; 11 (Supl.2): 110-4.

SOUZA E. A.; OLIVEIRA G. A. F.; MIRANDA E. R.; COUTINHO S. G.; FILHO G. P.; WAECHTER H. N. 2016. Alternativas epistemológicas para o design da informação: a forma enquanto conteúdo. Infodesign, São Paulo, v. 16, n. 2, p. 107 - 118.

TV ESCOLA. 2011. Sua escola, nossa escola - Alfabetização, Recife, PE. In: Videoteca. <http://tvescola.mec.gov.br/tve/video/sua-escola-nossa-escola-alfabetizacao-recife-pe>, 13.06.2017.

\section{Sobre o(a/s) autor(a/es)}

Mariana Hennes, MSc, UFAL, Brazil <mhennes.design@gmail.com>

Solange Coutinho, PhD, UFPE, Brazil <solangecoutinho@globo.com> 